\title{
DINÂMICA DO USO DO SOLO NA APA DA ESCARPA DEVONIANA E SEU ENTORNO
}

Tieme Breternitz Harfouche ${ }^{1}$, Ana Paula Dalla Corte ${ }^{2}$, Marieli Sabrina Ruza ${ }^{3}$, Franciel Eduardo Rex ${ }^{3}$

1. Acadêmica de Engenharia Florestal da Universidade Federal do Paraná,

Curitiba, Brasil. Email: (tiemebretzh@gmail.com).

2. Professora Doutora da Universidade Federal do Paraná, Curitiba, Brasil.

3. Mestre em Engenharia Florestal pela Universidade Federal do Paraná, Curitiba, Brasil.

Recebido em: 06/04/2019 - Aprovado em: 10/06/2019 - Publicado em: 30/06/2019 DOI: 10.18677/EnciBio_2019A55

\begin{abstract}
RESUMO
Este trabalho teve por objetivo realizar uma análise temporal do uso e cobertura do solo da APA da Escarpa Devoniana e de seu entorno, através de técnicas de sensoriamento remoto. Utilizou-se índices de vegetação confeccionados com imagens Landsat para os anos de 1986, 2006 e 2015. Após a segmentação, foi realizada uma classificação orientada a objeto do uso e cobertura do solo, resultando em sete classes. Avaliou-se a classificação com cálculo do índice Kappa. Os melhores resultados foram obtidos com o índice EVI para os anos de 1986 e 2006 e NDVI para o ano de 2015. A classificação demostrou que entre os anos de 1986 e 2015 houve um avanço de áreas antropizadas em $23 \%$ da APA, 17\% em sua área de entorno e 19\% no total da área estudada. Entre 1986 e 2006 houve redução no interior da APA de $12 \%$ das áreas compostas por vegetação natural. Já as classes de plantio florestal, agricultura e solo exposto aumentaram em $2 \%, 5 \%$ e $7 \%$, respectivamente. Os resultados refletem a alteração em áreas de composição natural na abrangência da APA e entorno.
\end{abstract}

PALAVRAS-CHAVE: Campos Gerais, classificação orientada a objeto, índices de vegetação.

\section{DYNAMICS OF THE SOIL USE IN ESCARPA DEVONIANA APA AND ITS BUFFER ZONE - PR}

\begin{abstract}
This study aims to perform a land use and land cover temporal analysis of Escarpa Devoniana APA and its buffer zone with remote sensing techniques. For that, vegetation indexes were compiled with Landsat images for the years 1986, 2006 and 2015. After segmentation, an object-oriented classification of land use and land cover was performed, resulting in seven classes. Classification was evaluated with Kappa index. The bests results were obtained with the EVI vegetation index for the years 1986 and 2006 and the NDVI for the year 2015.
\end{abstract}


Classification showed that between 1986 and 2015 there was an advance of anthropic areas in $23 \%$ of the APA area, $17 \%$ in its buffer zone and $19 \%$ in total area studied. Between 1986 and 2006 there was a reduction in the interior of the APA of $12 \%$ of the areas composed of natural vegetation, while the classes of forest plantations, agriculture and exposed soil increased by $2 \%, 5 \%$ and $7 \%$, respectively. The results reflect the change in areas of natural composition in APA and its buffer zone.

KEYWORDS: Campos Gerais, object-oriented classification, vegetation indexes.

\section{INTRODUÇÃO}

Criada no ano de 1992 pelo Decreto Estadual n 1.231, a Área de Proteção Ambiental (APA) da Escarpa Devoniana contempla um importante patrimônio natural e arqueológico dos Campos Gerais do Paraná (FERREIRA, 2018). Seu relevo escarpado e estrutura sedimentar estabelecem limite físico entre o primeiro e o segundo planalto do estado (MELO et al., 2015).

As APAs têm o propósito de proteger os recursos bióticos e abióticos presentes em seus limites, bem como paisagens e traços de relevância cultural, regulando o decurso de ocupação das terras (BRASIL, 2000). Embora esteja incluída no Sistema Nacional de Unidades de Conservação (SNUC) como unidade de Uso Sustentável (IAP, 2004), a APA da Escarpa Devoniana vem sofrendo ações antrópicas desde a sua criação. Algumas das áreas naturais remanescentes têm sido transformadas em áreas cultivadas, tanto com prática agrícola como pecuária, acarretando em pressão ao patrimônio regional (OLIVEIRA et al., 2015).

De acordo com informações divulgadas pela mídia, um projeto de lei $\left(n^{\circ}\right.$ 527/2016) que tramita na Assembleia Legislativa do Paraná propõe a redução da área da APA de 392 mil ha para 126 mil ha, alegando que sua delimitação, na época de criação, usou tecnologias pouco avançadas, resultando na inclusão de áreas de produção já estabelecidas. Tal proposta tem levantado discussão entre autoridades políticas, instituições econômicas, de pesquisa e sindicados, permeando aspectos que abordam ameaça à conservação em contraste com a sustentabilidade ambiental e econômica.

Conforme Meneguzzo (2014), as políticas públicas não apresentam de maneira específica características inerentes à vegetação dos campos, matas de araucária e cerrado que constituem os ecossistemas dos Campos Gerais do Paraná. Ademais, os instrumentos legais do estado dirigidos à preservação e conservação ambiental não têm sido eficazes em fiscalizar e monitorar as atividades de uso do solo nas Unidades de Conservação dos Campos Gerais do Paraná, por não terem recebido atendimento desde sua criação.

Perante isso, o sensoriamento remoto apresenta-se como ferramenta essencial para resgatar e registrar o uso do solo, no decorrer do tempo, sob a superfície terrestre de determinada região, valendo-se de imagens em nível orbital para a detecção, mapeamento e quantificação de seus objetos (SAITO et al., 2016). Desse modo, é crescente o uso do mapeamento do uso e cobertura do solo em Unidades de Conservação para estudo e compreensão de impactos em áreas protegidas, bem como para constituir-se de subsídio em políticas públicas (SOUSA et al., 2016).

Diante desses fatos, o presente trabalho teve como objetivo realizar uma análise temporal do uso do solo dentro dos limites da APA da Escarpa Devoniana e 
seu entorno, através de técnicas de sensoriamento remoto, com vistas a subsidiar a discussão e embasamento para a tomada de decisão nas questões relacionadas à redução de seu perímetro.

\section{Caracterização da área de estudo}

\section{MATERIAIS E MÉTODOS}

A APA da Escarpa Devoniana tem sua localização ao leste do estado do Paraná, ocupando uma área de 392.363,38 ha que está distribuída em 12 municípios (Lapa, Balsa Nova, Porto Amazonas, Palmeira, Campo Largo, Ponta Grossa, Carambeí, Castro, Tibagi, Piraí do Sul, Jaguariaíva e Sengés) (IAP, 2004).

Conforme o Decreto no 1.231/92, sua criação teve por objetivo garantir a proteção do limite natural existente entre o primeiro e segundo planalto paranaense. Seus limites abrangem a faixa de Campos Gerais, constituindo um ecossistema que de modo peculiar engloba capões da floresta de araucária, afloramentos rochosos, matas de galerias, "canyons", além de vestígios arqueológicos e pré-históricos (Figura 1).
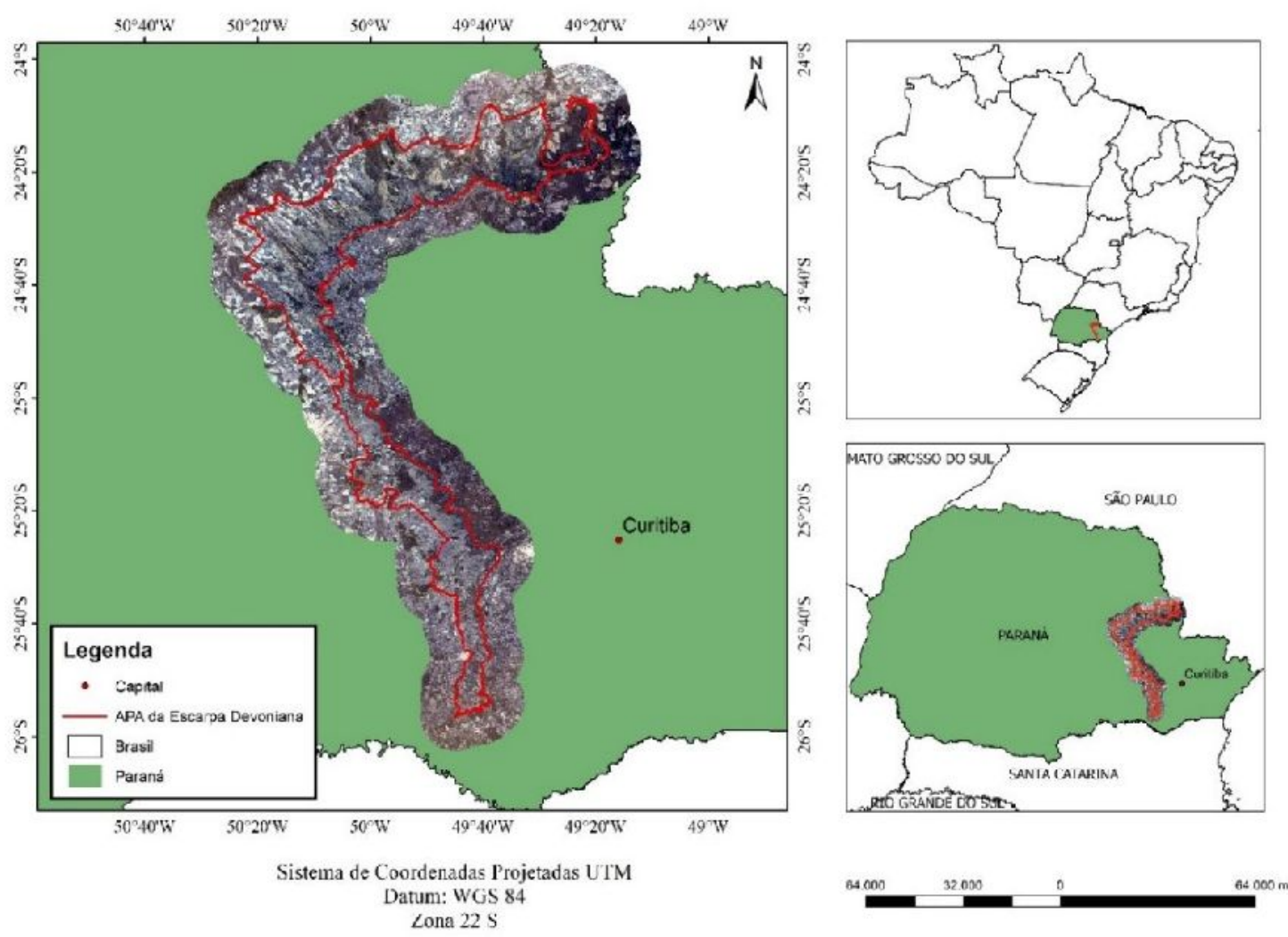

FIGURA 1. Localização da APA da Escarpa Devoniana no estado do Paraná e área de entorno com abrangência de $10 \mathrm{~km}$ a partir do seu limite. (Fonte: Os autores, 2017).

De acordo com o Plano de Manejo da APA (IAP, 2004), esta é composta de solos demasiadamente heterogêneos dentre eles Latossolos, Neossolos, Organossolos, Nitossolos e Argissolos coligados a áreas constituídas de relevo acidentado. 
A vegetação envolve áreas campestres, de cerrado e Floresta Ombrófila Mista (IAP, 2004). A região contempla os tipos climáticos Cfa e Cfb descritos por Köppen, caracterizando um clima subtropical com verão quente e temperado com verão ameno, respectivamente (ALVARES et al., 2014).

\section{Seleção e processamento das imagens}

Para o recobrimento da APA da Escarpa Devoniana, tanto em temporalidade como em área, foi necessário o uso de imagens geradas pelo satélite Landsat $5 \mathrm{com}$ o sensor TM (Thematic Mapper) e pelo Landsat $8 \mathrm{com}$ o uso do sensor OLI (Operational Land Imager), disponibilizadas pela USGS (United States Geological Survey). Priorizou-se imagens datadas em períodos semelhantes de cada ano, com menor quantidade ou ausência de nuvens. As características das imagens são descritas conforme a Tabela 1.

TABELA 1: Informações referentes às imagens Landsat 5 TM e Landsat 8 OLI utilizadas para o recobrimento da APA da Escarpa Devoniana e sua região de entorno.

\begin{tabular}{cccccc}
\hline Data & Sensor & $\begin{array}{c}\text { Elevação do } \\
\text { sol (221/77) }\end{array}$ & $\begin{array}{c}\text { Ângulo } \\
\text { Zenital }\end{array}$ & $\begin{array}{c}\text { Elevação do } \\
\text { sol (221/78) }\end{array}$ & $\begin{array}{c}\text { Ângulo } \\
\text { Zenital }\end{array}$ \\
\hline $04 / 08 / 86$ & TM & $31,71^{\circ}$ & $48,30^{\circ}$ & $30,57^{\circ}$ & $47,85^{\circ}$ \\
$12 / 10 / 06$ & TM & $48,18^{\circ}$ & $51,06^{\circ}$ & $47,08^{\circ}$ & $50,10^{\circ}$ \\
$04 / 08 / 15$ & OLI & $37,69^{\circ}$ & $40,13^{\circ}$ & $36,43^{\circ}$ & $39,67^{\circ}$ \\
\hline
\end{tabular}

As imagens foram corrigidas geometricamente com o software QGIS 2.14.12 para o sistema de coordenadas planas UTM (Universal Transversa de Mercator), meridiano 22S, Datum WGS-84 e aplicou-se a correção atmosférica com SemiAutomatic Classification Pluguin (SPC), usando o método DOS1 (Dark Object Subtraction 1) nas bandas correspondentes, o qual converte imagens Landsat de DN para reflectância de superfície. Foram utilizados os softwares ENVI para realizar a composição das bandas espectrais e o eCognition Definiens Professional LDH para segmentação e classificação. Posteriormente, o ArcGIS 10.4 foi utilizado para cálculo de áreas e geração dos mapas temáticos.

\section{Confecção dos índices de vegetação}

Os índices de vegetação NDVI, EVI e SAVI foram confeccionados no software QGIS 2.14.12. O Índice de Vegetação por Diferença Normalizada (NDVI) é determinado pela razão entre a diferença da reflectância nas regiões do infravermelho próximo (IV) e vermelho (V) e a sua soma (SILVA et al., 2017) (Equação 1). Este pode variar de -1 a 1, sendo que os valores mais próximos a 1 equivalem às áreas com porções mais elevadas de vegetação fotossinteticamente ativa, ao passo que os valores próximos a -1 indicam áreas com menor quantidade de vegetação (ROUSE et. al., 1974). 


$$
\begin{gathered}
N D V I=\frac{I N-V}{I V+V} \\
\text { SAVI }=\frac{(1+L)(I V+V)}{(L+I V+V)} \\
E V I=G \frac{I V-V}{I V+C 1 \cdot V-C 2 \cdot A+L}
\end{gathered}
$$

Sendo: $(\mathrm{IV})=$ Banda do infravermelho próximo; $\mathrm{V}=$ Banda do vermelho; $\mathrm{A}=$ banda do azul; $G=2.5$ (fator de ganho); $L=1$ (fator de correção para a interferência do solo); $\mathrm{C} 1=6$ e $\mathrm{C} 2=7.5$.

Já o Índice de Vegetação Ajustado para o Solo (SAVI) reduz a influência que a resposta espectral do solo tem sobre os índices de vegetação, a partir da inclusão do fator de ajuste (L), variando conforme o grau de densidade presente na área de estudo. Huete (1988) desenvolveu o índice que é obtido por meio da Equação 2. O fator $L$ poderá assumir o valor de 1,$0 ; 0,5$ ou 0,25 , que respectivamente são atribuídos se a cobertura vegetal da área é de baixa, intermediária ou alta densidade. Neste trabalho optou-se por atribuir 1 ao valor deste fator.

O Índice de Vegetação Melhorado (EVI) diminui as influências do solo e atmosfera, tendo, portanto, mais resistência a esses efeitos (HUETE et al., 2002). Este índice é aplicado através da Equação 3. Os valores atribuídos ao G, L, C1 e C2 foram determinados conforme Huete et al. (1997).

Após serem calculados os índices de vegetação, criou-se um buffer de $10 \mathrm{~km}$ a partir do perímetro da APA da Escarpa Devoniana, correspondente à sua área de entorno. Desse modo, a área da APA, juntamente com o entorno, totalizam uma área de 159.247 ha.

As imagens com os índices calculados foram exportadas para o software eCognition Definiens Professional LDH, o qual foi utilizado em duas etapas. Primeiramente cada imagem foi incorporada ao software e realizada a segmentação adotando para o parâmetro de escala (Scale parameter) o valor 15. Em seguida, as imagens foram classificadas mediante o método de Classificação Orientada a Objeto, usando o algoritmo de classificação pelo vizinho mais próximo (nearest neighbour), que separa a seleção dos atributos para amostragem. A classificação da área foi distribuída em 7 classes: vegetação nativa, estepe e afloramento rochoso, plantio florestal, agricultura, solo exposto, área urbana, água e outros.

A avaliação da acurácia para os resultados da classificação do uso e cobertura do solo foi verificada a partir da distribuição de 100 pontos amostrais aleatórios gerados na área. Os pontos foram gerados no software ArcGIS a partir da ferramenta "Create Random Points"; "Extract Values to Points"; convertidos para KML "Layer to KML", e conferidos em imagens do Google Earth, como referência de validação.

Posteriormente, foi elaborada uma matriz de confusão a qual distribui as percentagens de pixels, sejam eles classificados de maneira correta ou incorreta e efetuado o cálculo do Índice Kappa (k), o qual determina a qualidade da classificação adaptada de Landis e Koch (1977) que menciona: $\mathrm{K}<0,2$ - qualidade ruim; $\mathrm{K}$ entre 0,2 e 0,4 - qualidade razoável; $\mathrm{K}$ 
entre 0,4 e 0,6 - qualidade boa; $\mathrm{K}$ entre 0,6 e 0,8 - qualidade muito boa e $\mathrm{K}>0,8$ qualidade excelente.

Os índices de vegetação que apresentaram o melhor resultado para o coeficiente Kappa foram selecionados para a verificação das áreas correspondentes ao uso do solo na análise temporal.

\section{RESULTADOS E DISCUSSÃO}

Após os procedimentos aplicados, obteve-se como resultado as imagens classificadas para todos os anos. Como pode ser observada na Tabela 2, a qualidade das classificações foi considerada muito boa para o índice NDVI no ano de 2015 e boa para os demais, conforme a classificação de Landis e Koch (1977).

TABELA 2. Resultado do coeficiente Kappa para a classificação do uso do solo com os índices de vegetação nos anos de 1986, 2006 e 2015.

\begin{tabular}{cccc}
\hline \multicolumn{5}{c}{ ÍNDICE KAPPA DA CLASSIFICAÇÃO } \\
\hline \multicolumn{4}{c}{ Índices de Vegetação } \\
\hline Ano & EVI & NDVI & SAVI \\
\hline 1986 & 0,57 & 0,55 & 0,57 \\
2006 & 0,63 & 0,52 & 0,52 \\
2015 & 0,55 & 0,71 & 0,55 \\
\hline
\end{tabular}

Os índices EVI e SAVI apresentaram o mesmo valor de coeficiente Kappa na classificação para o ano de $1986(0,57)$, sendo superior ao NDVI, com 0,55. Para o ano de 2006 o EVI apresentou o maior valor $(0,63)$ dentre os demais. Esse índice aperfeiçoa o sinal da vegetação e é mais sensível às regiões de alta biomassa (HUETE, 2002), podendo ser indicativo de uma maior quantidade presente de vegetação nos anos de 1986 e 2006 em relação a 2015.

O NDVI obteve melhor resultado para o ano de 2015, apresentando um coeficiente Kappa de 0,71, que possivelmente obteve esse valor devido a imagem possuir resolução radiométrica de 16 bits e resolução espacial de $15 \mathrm{~m}$. Este índice de vegetação é utilizado como ferramenta de construção para traçar perfis temporais e sazonais das atividades da vegetação. Portanto, proporciona comparações interanuais de monitoramento da superfície terrestre nos perfis analisados (PONZONI et al., 2012; ROBINSON et al., 2017; BEZERRA et al., 2018).

A partir dos resultados da validação pelo coeficiente Kappa, foram selecionadas as imagens com os índices de vegetação EVI para os anos de 1986 e 2006, e NDVI no ano de 2015, para averiguação da porcentagem de área em cada classe de uso do solo. As classificações para os anos de 1986, 2006 e 2015 na área de estudo, encontram-se quantificadas nas Tabelas 3, 4 e 5, mostrando a área na qual cada classe está distribuída conforme Figura 2.

No ano de 1986 a APA ainda não havia sido criada. Contudo, percebe-se na Tabela 3 que neste ano havia um predomínio da vegetação nativa juntamente com a classe de estepe e afloramento rochoso, totalizando $70 \%$ da área atual da APA; $60 \%$ de seu entorno e $64 \%$ da área total estudada (APA + entorno). 
TABELA 3. Área e porcentagem de uso do solo para as diferentes classes com utilização do índice de vegetação EVI para a APA da Escarpa Devoniana no ano de 1986.

\begin{tabular}{|c|c|c|c|c|c|c|}
\hline \multirow[b]{2}{*}{ Usos do solo } & \multicolumn{2}{|c|}{ Área da APA } & \multicolumn{2}{|c|}{ Área de entorno } & \multicolumn{2}{|c|}{$\begin{array}{l}\text { APA + Área de } \\
\text { entorno }\end{array}$} \\
\hline & $\begin{array}{c}\begin{array}{c}\text { Área } \\
\text { (Mil ha) }\end{array}\end{array}$ & (\%) & $\begin{array}{c}\begin{array}{c}\text { Área } \\
\text { (Mil ha) }\end{array}\end{array}$ & (\%) & $\begin{array}{c}\begin{array}{c}\text { Área } \\
\text { (Mil ha) }\end{array}\end{array}$ & $(\%)$ \\
\hline Vegetação nativa & 89 & 23 & 265,7 & 35 & 354,7 & 31 \\
\hline $\begin{array}{l}\text { Estepe e afloramento } \\
\text { rochoso }\end{array}$ & 184,1 & 47 & 195,1 & 25 & 379,2 & 33 \\
\hline Plantio florestal & 32,1 & 8 & 79,9 & 10 & 111,9 & 10 \\
\hline Agricultura & 15,3 & 4 & 58,4 & 8 & 73,7 & 6 \\
\hline Solo exposto & 66,8 & 17 & 148,9 & 19 & 215,7 & 19 \\
\hline Área urbana & 2,9 & 1 & 14,6 & 2 & 17,5 & 2 \\
\hline Água & 2 & 1 & 3,9 & 1 & 5,8 & 1 \\
\hline Outros & 0,1 & 0,02 & 0,6 & 0,1 & 0,7 & 0,1 \\
\hline Total & 392,4 & 100 & 766,9 & 100 & $1.159,2$ & 100 \\
\hline
\end{tabular}

Após 20 anos, nota-se uma mudança na cobertura da terra no interior da APA (Tabela 4), com uma redução de $12 \%$ de áreas compostas pela vegetação natural, uma vez que $56 \%$ de sua área de 392,4 mil ha contemplam vegetação nativa, estepe e afloramento rochoso. As classes de plantio florestal, agricultura e solo exposto apresentaram um aumento de $2 \%, 5 \%$ e $7 \%$ na área da APA em relação a 1986, respectivamente.

De acordo com Zecchin et. al. (2017), a diminuição de áreas naturais nos Campos Gerais, a partir dos anos 90, é marcada pelo avanço do setor agrícola. Esse fato contribuiu para a substituição de áreas pertencentes a comunidades por grandes proprietários, o que afeta negativamente a identidade sociocultural dos Campos Gerais (SILVA, 2017).

Dalazoana e Moro (2011) apontam que a expansão da silvicultura também é um fator de pressão antrópica nos campos nativos do Paraná, além de atividades pecuárias agrícolas e de turismo. Foram observados plantios florestais e avanço agrícola irregular em Áreas de Preservação Permanente dentro da APA da Escarpa Devoniana em estudo de Pontes et al. (2018), por meio de imagens Google Earth no período de 2002 a 2017. 
TABELA 4. Área e porcentagem de uso do solo para as diferentes classes com utilização do índice de vegetação EVI para a APA da Escarpa Devoniana no ano de 2006.

\begin{tabular}{cccccccc}
\hline & \multicolumn{2}{c}{ Área da APA } & \multicolumn{2}{c}{ Área de entorno } & \multicolumn{2}{c}{$\begin{array}{c}\text { APA + Área de } \\
\text { entorno }\end{array}$} \\
\hline Usos do solo & $\begin{array}{c}\text { Área } \\
\text { (Mil ha) }\end{array}$ & $\begin{array}{c}\text { (\%) } \\
\text { Área } \\
\text { (Mil ha) }\end{array}$ & $\begin{array}{c}\text { (\%) } \\
\text { Área } \\
\text { (Mil ha) }\end{array}$ & $(\%)$ \\
\hline $\begin{array}{c}\text { Vegetação nativa } \\
\text { Estepe e afloramento } \\
\text { rochoso }\end{array}$ & 109,2 & 28 & 266,5 & 35 & 375,7 & 32 \\
$\begin{array}{c}\text { Plantio florestal } \\
\text { Agricultura }\end{array}$ & 38,8 & 10 & 93,7 & 12 & 132,5 & 11 \\
Solo exposto & 35,9 & 9 & 81,2 & 11 & 117,1 & 10 \\
Área urbana & 28,4 & 24 & 213,8 & 28 & 307,2 & 26 \\
Água & 2,1 & 1 & 13,0 & 2 & 15,1 & 1 \\
Outros & 0,03 & 0,01 & 0,1 & 0,02 & 0,2 & 0,01 \\
\hline Total & $\mathbf{3 9 2 , 4}$ & $\mathbf{1 0 0}$ & $\mathbf{7 6 6 , 9}$ & $\mathbf{1 0 0}$ & $\mathbf{1 . 1 5 9 , 2}$ & $\mathbf{1 0 0}$ \\
\hline
\end{tabular}

Para o ano de 2015 (Tabela 5), 47\% do total da APA da Escarpa Devoniana (186 mil ha) e 44\% de sua área de entorno (335 mil ha), apresentaram ocupação por áreas não antropizadas (vegetação nativa, estepe e afloramento rochoso e água). Em comparação com o ano de 2006, houve um decréscimo de $10 \%$ na composição natural dentro dos limites da APA e $4 \%$ em sua área de entorno. As classes de agricultura e solo exposto compuseram $35 \%$ da área da APA, além de $17 \%$ serem classificados como plantio florestal.

TABELA 5. Área e porcentagem de uso do solo para as diferentes classes com utilização do índice de vegetação NDVI para a APA da Escarpa Devoniana no ano de 2015.

\begin{tabular}{|c|c|c|c|c|c|c|}
\hline \multirow[b]{2}{*}{ Usos do solo } & \multicolumn{2}{|c|}{ Área da APA } & \multicolumn{2}{|c|}{ Área de entorno } & \multicolumn{2}{|c|}{$\begin{array}{c}\text { APA + Área de } \\
\text { entorno }\end{array}$} \\
\hline & $\begin{array}{c}\text { Área } \\
\text { (Mil ha) }\end{array}$ & $(\%)$ & $\begin{array}{c}\text { Área } \\
\text { (Mil ha) }\end{array}$ & $(\%)$ & $\begin{array}{c}\text { Área } \\
\text { (Mil ha) }\end{array}$ & (\%) \\
\hline Vegetação nativa & 115,2 & 29 & 271,1 & 35 & 386,3 & 33 \\
\hline $\begin{array}{c}\text { Estepe e afloramento } \\
\text { rochoso }\end{array}$ & 68,3 & 17 & 57,9 & 8 & 126,1 & 11 \\
\hline Plantio florestal & 65,5 & 17 & 138,1 & 18 & 203,6 & 18 \\
\hline Agricultura & 62,0 & 16 & 123,9 & 16 & 185,8 & 16 \\
\hline
\end{tabular}




\begin{tabular}{ccccccc} 
Solo exposto & 75,2 & 19 & 150,5 & 20 & 225,7 & 19 \\
Área urbana & 3,7 & 1 & 18,7 & 2 & 22,4 & 2 \\
Água & 2,6 & 1 & 6,5 & 1 & 9,1 & 1 \\
Outros & 0,04 & 0,01 & 0,1 & 0,02 & 0,2 & 0,02 \\
\hline Total & $\mathbf{3 9 2 , 4}$ & $\mathbf{1 0 0}$ & $\mathbf{7 6 6 , 9}$ & $\mathbf{1 0 0}$ & $\mathbf{1 . 1 5 9 , 2}$ & $\mathbf{1 0 0}$ \\
\hline
\end{tabular}

Nos limites da APA, as áreas de plantio florestal e agricultura cresceram 7\%, comparativamente com o ano de 2006, enquanto que o solo exposto diminuiu $5 \%$, provavelmente devido à rotação de culturas e crescimento da vegetação cultivada. De 1986 a 2015, os resultados mostram que a área antropizada na APA aumentou em $23 \% ; 17 \%$ em seu entorno e $19 \%$ no total da área estudada. A classificação do uso e cobertura do solo nos anos estudados pode ser observada na Figura 2.
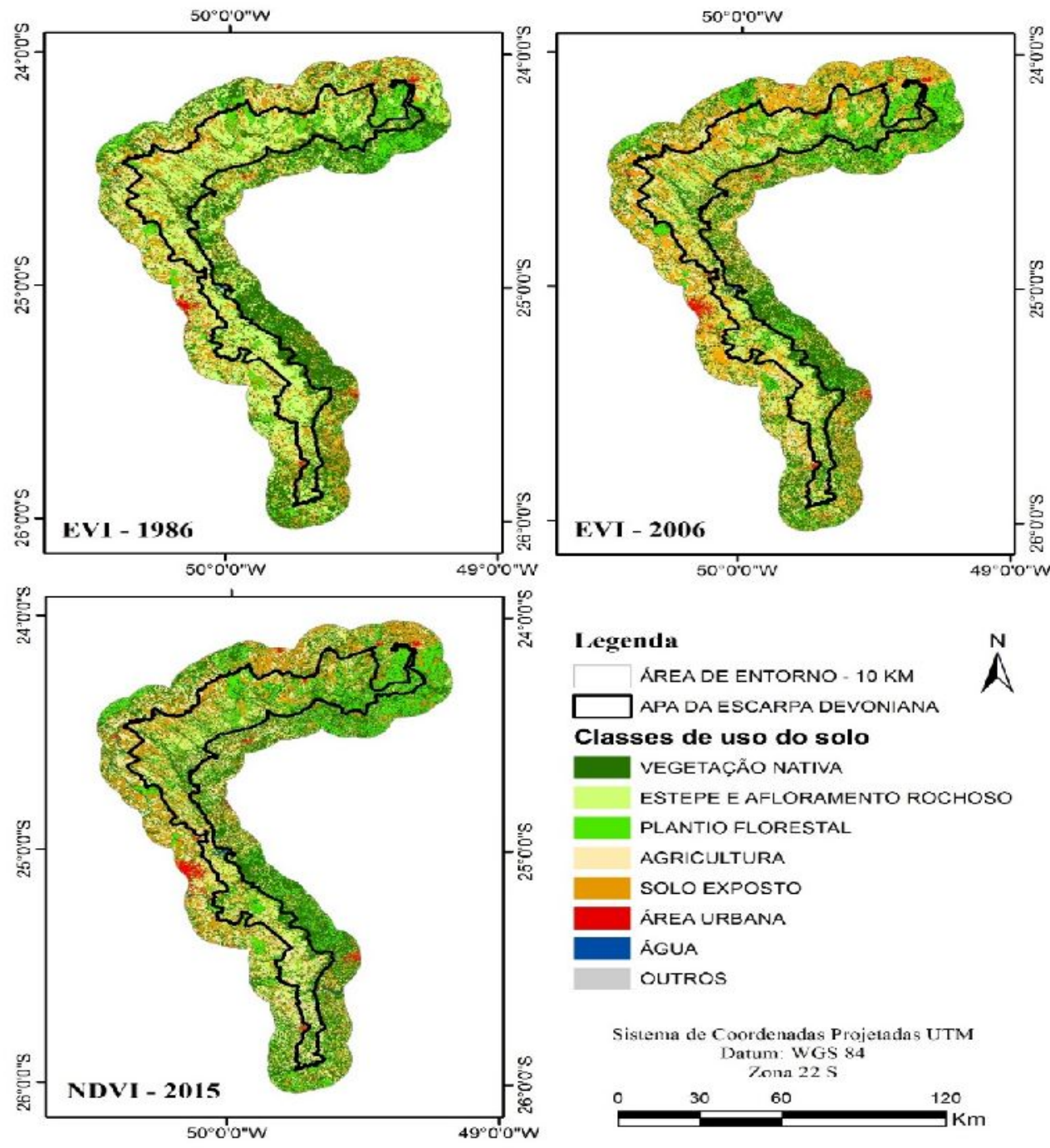

FIGURA 2: Classificação do uso e cobertura da APA da Escarpa Devoniana e sua área de entorno para os anos de 1986, 2006 e 2015 (Fonte: Os autores, 2017). 
Vale ressaltar que o novo Código Florestal (2012), trouxe consigo o conceito de áreas consolidadas. Estas foram denominadas áreas cuja ocupação antrópica, incluindo edificações, benfeitorias ou atividades agrossilvipastoris, foram anteriores a 22 de julho de 2008. As áreas consolidadas no interior da APA já revelam uma perda em sua cobertura e composição natural até o ano de 2008, em vista ao aumento da antropização ao longo desses anos.

Perante isso, para que uma APA cumpra sua função de Unidade de Conservação, faz-se necessária sua gestão e elaboração do plano de manejo para a área ocupada (ESTEVES; SOUZA, 2014), pois dentre outras consequências, o impacto gerado pela ação humana em unidades de conservação altera habitats, a biodiversidade, limita a disponibilidade de recursos naturais e reduz a ocorrência de espécies nativas (CHIVIAN; BERNSTEIN, 2008).

A Figura 3 apresenta, em vermelho, as áreas cujo agrupamento das classes é caracterizado pela ação antrópica (plantio florestal, agricultura, solo exposto e área urbana), bem como as classes, em verde, que não representam antropização (vegetação nativa, estepe e afloramento rochoso e água).

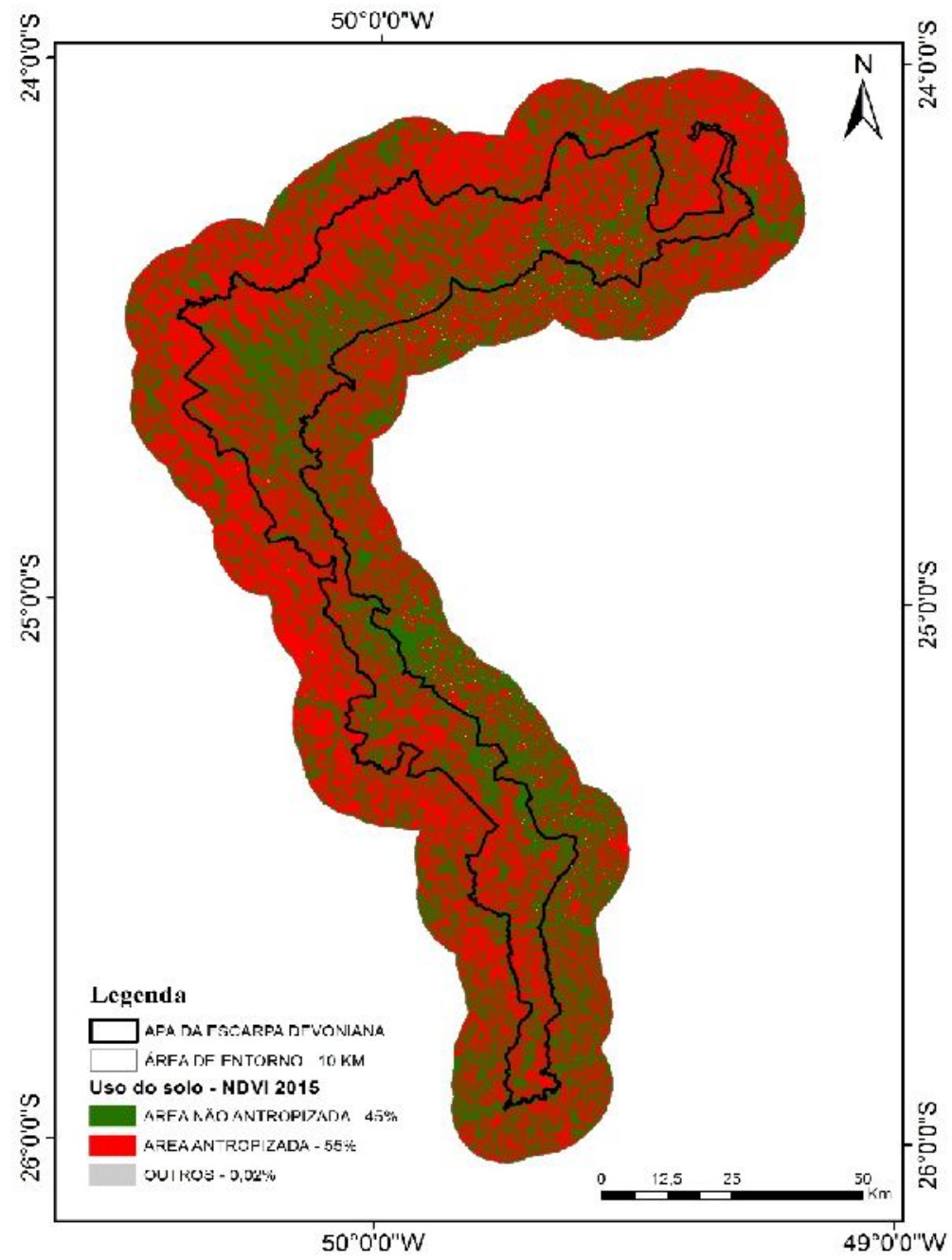

FIGURA 3 - Classificação do uso do solo da APA da Escarpa Devoniana e sua área de entorno com o uso do índice de vegetação NDVI no ano de 2015 (Fonte: Os autores, 2017). 
Um estudo realizado por Rosa et. al. (2017), com imagens Landsat-5 TM e Landsat-8 OLI, mostra as alterações ocorridas na cobertura do solo entre os anos de 1992 e 2017 na APA da Escarpa Devoniana. Constatou-se que no ano de 2017, $43,9 \%$ da área da APA era composta de paisagem natural (água, campos e floresta), e 56,1\% caracterizada pela paisagem alterada (agricultura, solo exposto e reflorestamento de exóticas), dos quais $42,2 \%$ foram classificados como sendo agricultura e solo exposto e aproximadamente 14\% como reflorestamento de exóticas. Esses resultados foram parecidos com os valores encontrados no presente trabalho.

Ainda que seja uma Unidade de Conservação de Uso Sustentável, permitindo a manutenção de atividades humanas, os resultados apontam que o uso tem aumentado tanto no interior da APA quanto em seu entorno. Consoante ao exposto, Fauro et al. (2016) afirmam que o revés territorial oriundo de questões referentes ao uso e ocupação do espaço se sobrepõe a medidas técnicas estatais dirigidas as Unidades de Conservação. Ademais, Feder e Mattos (2019) argumentam que além das inconstitucionalidades que o novo projeto de Lei apresenta, a redução do atual perímetro da APA culminaria em retrocesso do que outrora foi conquistado ambientalmente com sua criação.

As dificuldades encontradas para o trabalho se concentram no fato de não haver imagens de satélite com melhores resoluções, abrangendo toda área de interesse a custos não proibitivos para um trabalho acadêmico. Sugere-se que para uma melhor acurácia da validação da classificação, esta seja realizada através de pontos de controle para uma verdade terrestre.

\section{CONCLUSÃO}

As alterações no uso e cobertura do solo, na APA da Escarpa Devoniana e seu entorno, a partir de 1986 até 2015 foi notória, constando uma maior transição principalmente de vegetação natural para cultivo agrícola.

O uso e incorporação dos índices de vegetação em imagens de satélite auxiliaram em melhores resultados para identificar processos de perda e alteração de cobertura vegetal. O índice EVI apresentou maior aproximação da realidade nos anos de 1986 e 2006 e o NDVI apresentou-se mais adequado no ano de 2015.

O sensoriamento remoto aplicado ao estudo das mudanças do uso do solo, incorporando os índices de vegetação, mostrou-se satisfatório para identificar modificações em períodos específicos, podendo ser subsídio para monitoramento, gestão e planejamento de medidas que contribuam para o cumprimento do propósito que as Unidades de Conservação de Uso Sustentável e especificamente a APA da Escarpa Devoniana possuem.

\section{REFERÊNCIAS}

ALVARES, C. A.; STAPE J. L.; SENTELHAS P. C.; GONÇALVES, J. L. M.; SPAROVEK, G. Koppen's climate classification map for Brazil. Meteorologische Zeitschrift, v. 22, n. 6, p. 711-728, (published online January 2014). Disponível em: https://dx.doi.org/10.1127/0941-2948/2013/0507. DOI: 10.1127/09412948/2013/0507

BEZERRA, U. A.; OLIVEIRA, L. M. M.; CANDEIAS, A. L. B.; SILVA, B. B.; LEITE, A. C. L. S. et al. Comparativo do Índice de Vegetação de Diferença Normalizada (NDVI) entre os Sensores OLI - Satélite Landsat-8 e 
MSI - Satélite Sentinel-2 em Região Semiárida. Anuário do Instituto de Geociências - UFRJ, v. 41, n. 3, p. 167-177, 2018. Disponível em: http://www.anuario.igeo.ufrj.br/2018_03/2018_3_167_177.pdf. Acesso em: 18 mar. 2019.

BRASIL. Lei no 9.985, de 18 de julho de 2000. Regulamenta o art. 225, $\S 10$, incisos I, II, III e VII da Constituição Federal, institui o Sistema Nacional de Unidades de Conservação da Natureza e dá outras providências.

CHIVIAN, E.; BERNSTEIN, A. Sustaining life: How human health depends on biodiversity. New York: Oxford University Press, 2008. 542 p.

DALAZOANA, K.; MORO, R. S. Riqueza específica em áreas de campo nativo impactadas por visitação turística e pastejo no Parque Nacional dos Campos Gerais, PR. Floresta, v. 41, n. 2, p. 387-396, 2011. Disponível em: http://dx.doi.org/10.5380/rf.v41i2.22762. DOI: 10.5380/rf.v41i2.22762

ESTEVES, A. O.; SOUZA, M. P. Avaliação Ambiental Estratégica e as Áreas de Proteção Ambiental. Engenharia Sanitária e Ambiental, v. 19, p. 77-86, 2014. Disponível em: http://dx.doi.org/10.1590/S1413-41522014019010000443 DOI: 10.1590/S1413-41522014019010000443

FAURO, J. C. S.; TONIOL, F. P. F; SERRA, E. Técnicas agrícolas, preservação e impactos ambientais na região Oeste do Paraná. Ra'e Ga, v. 36, p. 302-321, 2016. Disponível em: http://dx.doi.org/10.5380/raega.v36i0.43667 DOI: 10.5380/raega.v36i0.43667

FEDER, M. M.; MATTOS, M. M. C. Análise do projeto de lei estadual no 527/2016: é constitucional a alteração da área de proteção ambiental da região da escarpa devoniana?. REDUFES, v. 1, n. 1, 2019. Disponível em: http://www.periodicos.ufes.br/redufes/article/view/23356. Acesso em: 12 mar. 2018

FERREIRA, M. W. S.; BRILHA, J. B. R.; CERÂNTOLA, A. P. C. Legislação ambiental brasileira e geoconservação: análise comparativa do enquadramento legal no Brasil, Portugal e Espanha. Revista do Instituto Geológico, v. 39, n. 2, p. 17-26, 2018. Disponível em: http://dx.doi.org/10.5935/0100-929X.20180006 DOI: 10.5935/0100929X.20180006

HUETE, A. R. A. Soil-Adjusted Vegetation Index (SAVI). Remote Sensing of Environment, v. 25, n. 3, p. 295-309, ago. 1988. Disponível em: https://doi.org/10.1016/0034-4257(88)90106-X. DOI: 10.1016/0034-4257(88)90106-X

HUETE, A; LIU, H. Q.; BATCHILY, K.; LEWEEN, W. A. A Comparison of vegetation indices over a global set of TM images for EOS-MODIS. Remote Sensing of Environment, v. 59, n. 3, p.440-451, mar. 1997. Disponível em: https://doi.org/10.1016/S0034-4257(96)00112-5. DOI: 10.1016/S00344257(96)00112-5 
HUETE, A.; DIDAN, K.; MIURA, T.; RODRIGUEZ, E. P.; GAO, X.; FERREIRA, L. G. Overview of the radiometric and biophysical performance of the MODIS vegetation indices. Remote Sensing of Environment, v. 83, n. 1-2, p. 195-213, 2002. Disponível em: https://doi.org/10.1016/S0034-4257(02)00096-2. DOI: 10.1016/S0034-4257(02)00096-2

IAP. Instituto Ambiental do Paraná. Plano de manejo da Área de Proteção Ambiental da Escarpa Devoniana. 2004. Disponível em: http://www.iap.pr.gov.br/arquivos/File/Plano_de_Manejo/APA_Escarpa_Devoniana/1 APA_PM.pdf Acesso em: 09 jun. 2017.

LANDIS, R.; KOCH, G. G. The measurement of observer agreement for categorical data. Biometrics, v. 33, n. 1, p. 159-174, mar. 1977. Disponível em: https://www.dentalage.co.uk/wp-

content/uploads/2014/09/landis_j__koch_gg_1977_kappa_and_observer_agreemen t.pdf. Acesso em: 15 out. 2017.

MELO, M. S.; GUIMARÃES, G. B.; CHINELATTO, A. L.; GIANNINI, P. C. F.; PONTES, H. S. et al. Kaolinite, illite and quartz dissolution in the karstification of Paleozoic sandstones of the Furnas Formation, Parana Basin, Southern Brazil. Journal of South American Earth Sciences, v. 63, p. 20-35, 2015. Disponível em: https://doi.org/10.1016/j.jsames.2015.06.011. DOI: 10.1016/j.jsames.2015.06.011

MENEGUZZO, I. S. A efetividade das políticas ambientais para a conservação da natureza nos parques estaduais dos Campos Gerais do Paraná. Terr@Plural, v.8, n. 1, p. 91-106, 2014. Disponível em: http://dx.doi.org/10.5212/TerraPlural.v.8i1.0005 DOI: 10.5212/TerraPlural.v.8i1.0005

OLIVEIRA, F. C. P.; OKA-FIORI, C.; MELO, M. S.; PARELLADA, C. I. As pinturas rupestres da Região de Piraí da Serra - Paraná. Ra'e Ga, v. 33, p. 171-197, 2015. Disponível em: http://dx.doi.org/10.5380/raega.v33i0.35945 DOI: 10.5380/raega.v33i0.35945

PARANÁ. Decreto n 1.231, de 27 de março de 1992. Cria a Área de Proteção Ambiental - APA da Escarpa Devoniana com base nas Leis Federais nํㅗ 6.902, de 27 de abril de 1981 e 6.938 , de 31 de agosto de 1981, com as alterações da Lei no 7.804, de 18 de julho de 1989 e no Decreto no 99.274, de 06 de junho de 1990. Legislação do Estado do Paraná, Curitiba, 27 de março de 1992. Disponível em: http://www.icmbio.gov.br/cepsul/images/stories/legislacao/Decretos/1992/dec_pr_12 31_1992_uc_apaestadualescarpadevoniana_camposgerais_pr.pdf. Acesso em: 22 abr. $201 \overline{7}$.

PONTES, H. S.; MASSUQUETO, L. L.; GUIMARÃES G. B.; ROCHA, C. H. O projeto de lei de redução da APA da Escarpa Devoniana: ameaças à proteção dos campos nativos e cavernas dos Campos Gerais do Paraná, Brasil. Terr@Plural, v. 12, n. 2, p. 211-237, 2018. Disponível em: https://doi.org/10.5212/TerraPlural.v.12i2.0005 DOI: 10.5212/TerraPlural.v.12i2.0005 
PONZONI, F. J.; SHIMABUKURO Y. E.; KUPLICH, T. M. Sensoriamento remoto da vegetação. 2.ed. São Paulo: Oficina de Textos, 2012. 160p.

ROBINSON, N. P.; ALLRED, B. W.; JONES, M. O.; MORENO, A.; KIMBALL, J. S. et al. Dynamic Landsat Derived Normalized Difference Vegetation Index (NDVI) Product for the Conterminous United States. Remote Sensing, v. 9, n. 8, p. 863, 2017. Disponível em: https://doi.org/10.3390/rs9080863 DOI: $10.3390 /$ rs9080863

ROSA, J. Z.; ROCHA, C. H.; RIBEIRO, S. R. A. Sensoriamento remoto aplicado à análise das alterações da paisagem na APA da Escarpa Devoniana - Paraná Brasil. Anais do IV Simpósio Brasileiro de Patrimônio Geológico e II Encontro Luso-Brasileiro de Patrimônio Geomorfológico e Geoconservação. Ponta Grossa, 2017, p. 196-200.

ROUSE, J. W.; HASS, R. H.; DEERING, D. W.; SCHELL, J. A. Monitoring the vernal advancement and retrogradiation (green wave effect) of natural vegetation. Austin: Texas A. M. University, College Station, 1974. 8p.

SAITO, N. S.; ARGUELLO, F. V. P.; MAURÍCIO, M. A.; SANTOS, A. R.; EUGENIO, F. C. et al. Uso da tecnologia para análise temporal da cobertura florestal. CERNE, v. 22, n. 1, p. 11-18, 2016. Disponível em: http://dx.doi.org/10.1590/01047760201622011935 DOI: 10.1590/01047760201622011935

SILVA, E. A. Identidades comunitárias nos Campos Gerais. In: Análise socioambiental do Projeto de Lei 527/2016, PR, referente à redução da área de Proteção Ambiental da Escarpa Devoniana, Campos Gerais. Parecer técnico, 61 p., Curitiba, 2017.2 Disponível em: http://www.sindiseab.org.br/assets/uploads/download/PARECER\%20GERAL_Final.p df. Acesso em: 23 set. 2018

SILVA, L. A.; LEITE, M. R.; VELOSO, G. A. NDVI como indicador de alterações nos sistemas de usos da terra e no albedo de superfície no município de Várzea da Palma (Minas Gerais). Revista Geonordeste, n. 2, p. 76-94, 2017. Disponível em: https://seer.ufs.br/index.php/geonordeste/article/view/7048/pdf. Acesso em: 01 abr. 2019

SOUSA, E. R.; CASTRO, A. C. L.; AZEVEDO, J. W. J.; ARAUJO, G. M. C. Evolução espaço-temporal do uso e cobertura da terra em áreas propostas para a implantação de unidades de conservação no município de Bacabeira-MA. Revista Espacios, v. 37, n. 12, p. 27, 2016. Disponível em: http://www.revistaespacios.com/a16v37n12/16371227.html. Acesso em: 01 abr. 2019.

ZECCHIN, A.; CASTELLA, R. M. B. Diversidade biológica da flora e fauna. In: Análise socioambiental do Projeto de Lei 527/2016, PR, referente à redução da área de Proteção Ambiental da Escarpa Devoniana, Campos Gerais. Parecer técnico, 61 p., Curitiba, 2017. Disponível em: http://www.sindiseab.org.br/assets/uploads/download/PARECER\% 20GERAL_Final.pdf. Acesso em: 23 set. 2018 